\title{
Chemical and isotopic composition of magmatic gases from the 1988 eruption of Klyuchevskoy volcano, Kamchatka
}

\author{
Yu.A. Taran ${ }^{\text {a }}$, A.M. Rozhkov ${ }^{\text {a }}$, E.K. Serafimova ${ }^{a}$ and A.D. Esikov ${ }^{b}$ \\ ${ }^{a}$ Institute of Volcanology, Petropavlovsk-Kamchatsky, 683006, USSR \\ ${ }^{b}$ Institute of Water Problems, 13/3 Sadovo-Chemogryazskaya St., Moscow, 103064 USSR
}

(Received February 9, 1990; accepted in revised form September 14, 1990)

\begin{abstract}
Taran, Yu.A., Rozhkov, A.M., Serafimova, E.K. and Esikov, A.D., 1991. Chemical and isotopic composition of magmatic gases from the 1988 eruption of Klyuchevskoy volcano, Kamchatka. J. Volcanol. Geotherm. Res., 46: 255-263.

Gas samples have been collected at the place of magma effusion during the 1988 flank eruption of Klyuchevskoy, for the first time in the course of studies at this volcano. The high-temperature gases $\left(1000-1100^{\circ} \mathrm{C}\right)$ are rich in water and halogens but depleted in sulphur. Their molar composition is close to chemical equilibrium at the collection temperature, while their oxidation state corresponds to redox conditions between FMQ and NNO buffers. The isotopic composition of the water $\left(\delta \mathrm{D}=-71\right.$ to $-44 \% 0 ; \delta^{18} \mathrm{O}=+6.3$ to $+8.4 \%$, versus SMOW) plots within the field of "primary magmatic" waters. The isotopic composition of $\mathrm{H}_{2}(\delta \mathrm{D}=-187 \%$ to $-160 \% 0)$ is consistent with isotopic equilibrium between $\mathrm{H}_{2}$ and $\mathrm{H}_{2} \mathrm{O}$ in the conditions of emission. Both the chemistry of the gases and the low $\delta^{13} \mathrm{C}$ of carbon dioxide $(-11.6 \% 0, \mathrm{PDB})$ suggest extensive magma outgassing occurred during the course of the eruption.
\end{abstract}

\section{Introduction}

In spring and summer 1988, during a flank eruption of Klyuchevskoy volcano, we succeeded in collecting high-temperature gases from the mere place of magma outpouring. It is the first time such a sampling could be done at Klyuchevskoy, after more than half a century of systematic observation. Previous conditions of eruptions had allowed to collect gases from only the surface of cooling lava flows or from cinder cones (Basharina, 1963; Serafimova, 1979). These samples were by $95 \%$ or more contaminated by air and their temperatures were lower than $600^{\circ} \mathrm{C}$.

Klyuchevskoy volcano, a huge stratovolcano (the height of the volcano is 4750 $\mathrm{m}$ a.s.l. and the volume of the edifice is more than $250 \mathrm{~km}^{3}$ ) belongs to the so-called
Klyuchevskoy volcanic group which is located in the Central Kamchatkan Depression, at the junction of the Kurile-Kamchatka and Aleutian island arcs. Lately, a wealth of data have been systemized on geophysics, petrology, on geochemistry of solid products of eruptions as well as on the dynamics of the activity of volcano (Kirsanov et al., 1973; Fedotov et al., 1988; Khrenov et al., 1989). The age of Klyuchevskoy is about 7 thousand years (I.V. Melekestsev, pers. commun., 1989). Its products are typical calc-alkaline basalts of aluminous to magnesian character. Cyclicity in the eruptive activity of the volcano has been noted. The last eruptive cycle, with simultaneous flank eruptions and explosive-effusive activity at the summit crater, was characterized by an upward migration of the vents of flank eruptions. Since 1980 all flank eruptions 
were purely effusive

The 1988 eruption occurred on the southern slope of Klyuchevskoy at an elevation of 4,100 $\mathrm{m}$ and lasted for more than 7 months (from January 29 to September 14). It was the longest of the cycle and the closest to the summit crater. The eruptive center, formed at the intersection of a radial fissure and ring fissure, opened on the upper slopes of the mountain. Lava flowing took place from the base of a small cinder cone which was formed during the course of the eruption. The width of the flow at the vent was $1.2-1.5 \mathrm{~m}$ and in May its rate was about $0.4 \mathrm{~m} / \mathrm{s}$.

\section{Sampling and analysis}

\section{Sampling}

Several gas samples were collected during the eruption. The present paper deals with four of them (air content is lesser than $95 \%$ ). Sample 1 (May 4) and sample 2 (July 18) were collected from the cone of splashing lava (hornito), approximately $3 \mathrm{~m}$ above the head of the lava flow. The diameter of the vent was about $0.7 \mathrm{~m}$ in May. Its inner part was incandescent and up to bright orange in color. Under the pressure of the gas, pieces of liquid lava were thrown up. The velocity of the gas jet in May was estimated at $15 \mathrm{~m} / \mathrm{s}$ and the gas discharge at about $6 \mathrm{~m}^{3} / \mathrm{s}$. The gas velocity varied according to occasional collapses of lava walls into the vent. These portions either were further blown out by the gas to heights of 6-10 $\mathrm{m}$ or were squeezed from the hornito in small lava flows. After clearing of the channel, the regime of gas release reconstituted. This type of activity persisted in July. In August, only a few narrow fissures at the top of lava cone occurred, but lava flowing rate was not changed. Samples 3 and 4 (August 21 and August 25, respectively) were collected from one of the fissures. At the time of sampling, gas from fissures escaped with a typical hissing. Flames of light blue color, the height of which was $10-30 \mathrm{~cm}$, were observed at night at the places of gas issue.

For sampling, a ceramic pipe, $40 \mathrm{~mm}$ in diameter, was plunged into the orifice of the hornito or into fissures of the lava cone. Inside this pipe we inserted a silica tube, connected to a series of gas absorbers by teflon and rubber links. Temperature at the sampling points was measured with an optical pyrometer.

Most gas samples were collected in evacuated bottles containing an alkaline solution $(\mathrm{NaOH}, 4 N)$. The gas was also aspired using a glass syringe of $100 \mathrm{~cm}^{3}$ through bubblers which were cooled by snow in order to sample both water condensate and gas into $230-\mathrm{cm}^{3}$ glass vessels.

\section{Analysis}

Unabsorbed gases in the bottles with alkaline solution $\left(\mathrm{O}_{2}, \mathrm{~N}_{2}, \mathrm{H}_{2}, \mathrm{CO}, \mathrm{CH}_{4}\right)$ were analyzed by chromatograph, using a 4-m-long molecular sieve column and a thermal conductivity detector. Argon was determined on a composite column with molecular sieves $\mathrm{CaA}$ and $\mathrm{NaX}$ (at room temperature, after Tsitsishvili et al., 1975). For isotopic analysis we separated $\mathrm{CO}_{2}$ (by freezing with liquid nitrogen) and $\mathrm{H}_{2}$ (by burning and subsequent reduction on uranium) from the other gases collected into the glass vessels.

"Acid" gases $\left(\mathrm{CO}_{2}, \mathrm{H}_{2} \mathrm{O}, \mathrm{SO}_{2}, \mathrm{HCl}\right.$ and $\mathrm{HF}$ ) in alkaline solutions were determined by wet chemistry and the proportions of $\mathrm{H}_{2} \mathrm{O}$ and $\mathrm{SO}_{2}$ were calculated by method of Giggenbach (1975). In samples 1 and 3 precipitation of elementary sulfur was noticeable. Because of poor knowledge of the redistribution of $\mathrm{H}_{2} \mathrm{~S}, \mathrm{~S}_{2}$ and $\mathrm{SO}_{2}$ in these two samples, only a total sulfur was reported.

\section{Results}

The analytical results are listed in Table 1 . Chemical compositions are given in 
TABLE 1

Chemical and isotopic composition of magmatic gases from Klyuchevskoy volcano (1988 eruption)

\begin{tabular}{|c|c|c|c|c|}
\hline $\begin{array}{l}\text { Date of sampling: } \\
\text { Number of sample: } \\
T\left({ }^{\circ} \mathrm{C}\right)\end{array}$ & $\begin{array}{l}\text { May } 4 \\
1 \\
1050\end{array}$ & $\begin{array}{l}\text { Jul } 18 \\
2 \\
1070\end{array}$ & $\begin{array}{l}\text { Aug } 21 \\
3 \\
1100\end{array}$ & $\begin{array}{l}\text { Aug } 25 \\
4 \\
1100\end{array}$ \\
\hline \multicolumn{5}{|c|}{ Chemical composition ( $\mu$ mole/mole $)$} \\
\hline $\mathrm{H}_{2} \mathrm{O}$ & 940000 & 908400 & 976000 & 977300 \\
\hline $\mathrm{H}_{2}$ & 11600 & 17000 & 6200 & 5900 \\
\hline $\mathrm{CO}_{2}$ & 24600 & 44700 & 500 & 1200 \\
\hline $\mathrm{CO}$ & 1100 & 1550 & $<5$ & 12 \\
\hline $\mathrm{H}_{2} \mathrm{~S}$ & 1700 & 500 & 1500 & 20 \\
\hline $\mathrm{SO}_{2}$ & & 1000 & & 900 \\
\hline $\mathrm{HCl}$ & 20200 & 22500 & 15300 & 14200 \\
\hline $\mathrm{HF}$ & 740 & 2900 & 3000 & 2500 \\
\hline $\mathrm{N}_{2}$ & * & $* *$ & 80 & 40 \\
\hline $\mathrm{Ar}$ & * & $* *$ & 0.38 & 0.32 \\
\hline $\mathrm{CH}_{4}$ & 7 & 13 & $<1$ & $<1$ \\
\hline \multicolumn{5}{|c|}{ Isotopic composition (\%o) } \\
\hline${ }^{18} \mathrm{O}_{\mathrm{H}_{2} \mathrm{O}}$ & - & +8.4 & +6.3 & +7.8 \\
\hline $\mathrm{D}_{\mathrm{H}_{2} \mathrm{O}}$ & - & -44 & -71 & -59 \\
\hline $\mathrm{D}_{\mathrm{H}_{2}}$ & - & -164 & -187 & -160 \\
\hline${ }^{13} \mathrm{C}_{\mathrm{CO}_{2}}$ & - & -11.6 & - & - \\
\hline \multicolumn{5}{|l|}{ Atomic ratios } \\
\hline $\mathrm{H} / \mathrm{C}$ & 77 & 41 & 9800 & 1640 \\
\hline $\mathrm{S} / \mathrm{C}$ & 0.066 & 0.035 & 3.0 & 0.76 \\
\hline $\mathrm{Cl} / \mathrm{F}$ & 27 & 7.8 & 5.1 & 5.7 \\
\hline $\mathrm{N}_{2} / \mathrm{Ar}$ & * & $* *$ & 210 & 125 \\
\hline
\end{tabular}

Air content in dry gas (volume $\%) ;{ }^{*}-83 ;{ }^{* *}-41$.

$\mu$ mole/mole, isotopic ones in $\delta$ per mil deviations with respect to international standards (SMOW for $\mathrm{H}_{2} \mathrm{O}$ and $\mathrm{H}_{2}$, PDB for carbon).

In samples 1 and 2 collected directly from hornitos, air contamination amounts to $83 \%$ and $41 \%$ of the anhydrous phase, respectively. Samples 3 and 4, collected from fissures of lava cone, contained almost no air. In those water-rich samples $\mathrm{CO}$ concentrations were close to the detection limit of our chromatographic technique. Methane has been detected only on samples 1 and 2 and its concentration is close to that corresponding to air addition, as inferred from the $\mathrm{N}_{2}$ content $\left(\sim 10^{-4} \%\right.$ in dry gas). The $\mathrm{N}_{2} / \mathrm{Ar}$ ratio of samples 3 and 4 is much higher than atmospheric ratio (83). Therefore elemental and isotopic analysis of noble gases could be done only for these two samples, the results of which will appear elsewhere.
The isotopic composition of water (Table 1) plots into the field typical of "primary magmatic" waters (Taylor, 1979) and, particularly water in the "driest" sample 2 is isotopically characteristic of "andesitic" magmatic waters (Sakai and Matsubaya, 1977; Allard, 1983; Poreda, 1985; Taran et al., 1989). Its magmatic origin thus is likely. The $\delta \mathrm{D}$ of $\mathrm{H}_{2}$ ranges from -187 to $-160 \%$ and allows to calculate equilibrium temperatures of about $1000-1199^{\circ} \mathrm{C}$ for isotopic exchange in the system $\mathrm{H}_{2}-\mathrm{H}_{2} \mathrm{O}$ (Table 2). Thus both species were in equilibrium at the emission.

The $\delta^{13} \mathrm{C}$ of $\mathrm{CO}_{2}(-11.6 \%)$, measured only in sample 2 , differs from "normal" mantle values $(-8$ to $-5 \%$ ). It also differs from $\delta^{13} \mathrm{C}$ of some high-temperature gases of island arcs and continental margins volcanoes (Allard, 1980, 1983; Javoy et al., 1986). Specially, it is comparable to the $\delta^{13} \mathrm{C}$ of $\mathrm{CO}_{2}$ from 


\section{TABLE 2}

Apparent equilibrium temperature of Klyuchevskoy gas samples, as inferred from either chemical or isotopic reactions, and calculated oxygen and sulfur fugacities

\begin{tabular}{lcccc}
\hline Sample number: & 1 & 2 & 3 & 4 \\
\hline$T^{\circ} \mathrm{C}$, measured & 1050 & 1070 & 1100 & 1100 \\
$T_{\mathrm{C}}$ & 1359 & 1047 & - & 1007 \\
$T_{\mathrm{S}}$ & - & 983 & - & 960 \\
$T_{\mathrm{H}}$ & - & 994 & 998 & 1089 \\
$\log f_{\mathrm{O}_{2}}(\mathrm{H})$ & -9.96 & -10.03 & -8.75 & -871 \\
$\log f_{\mathrm{O}_{2}}(\mathrm{C})$ & -10.53 & -10.00 & - & -8.40 \\
$\log f_{\mathrm{O}_{2}}(\mathrm{~S})$ & - & -10.73 & - & -9.70 \\
$\log f_{\mathrm{S}_{2}}$ & - & -4.98 & - & -6.68 \\
\hline
\end{tabular}

Note: $T_{\mathrm{C}}$ and $T_{\mathrm{S}}$ were calculated from eqs. (6) and (7), respectively; $T_{\mathrm{H}}$ was calculated from isotopic equilibrium $\mathrm{H}_{2}$ $\mathrm{H}_{2} \mathrm{O}$ (eq. 12) $\log f_{\mathrm{O}_{2}}(\mathrm{H}, \mathrm{C}, \mathrm{S})$ inferred from eqs. 8-10 and $\log f_{S_{2}}$ from eq. 11 . See text.

several Kamchatkan and Kurile volcanoes in fumarolic stage of activity (e.g. Menyailov et al., 1983; Taran, 1985; Taran et al., 1991).

\section{Gas and isotopic equilibria}

Based on thermodynamic constants for the following two reactions:

$$
\begin{aligned}
& \mathrm{CO}_{2}+\mathrm{H}_{2}=\mathrm{CO}+\mathrm{H}_{2} \mathrm{O} \\
& \mathrm{SO}_{2}+3 \mathrm{H}_{2}=\mathrm{H}_{2} \mathrm{~S}+2 \mathrm{H}_{2} \mathrm{O}
\end{aligned}
$$

one can estimate "apparent" equilibrium temperatures of gas mixtures. Then, once this temperatures calculated, we can estimate the corresponding "apparent" oxygen fugacity of the gas using the following equilibria:

$$
\begin{aligned}
& 2 \mathrm{CO}+\mathrm{O}_{2}=2 \mathrm{CO}_{2} \\
& 2 \mathrm{H}_{2}+\mathrm{O}_{2}=2 \mathrm{H}_{2} \mathrm{O} \\
& \mathrm{H}_{2} \mathrm{~S}+\mathrm{O}_{2}=\mathrm{SO}_{2}+\mathrm{H}_{2}
\end{aligned}
$$

The purpose of these calculations, whose results are given in Table 2, is to check whether the Klyuchevskoy magmatic gases were in equilibrium in the conditions of sampling, to evaluate the redox conditions of the melt-fluid system, and to elucidate the reasons of possible deviations from equilibrium.
In our case, such calculations were of interest since, on one hand, the gases collected and particularly samples 3 and 4 are rich in water - a feature rather typical for low- and midtemperature fumaroles of volcanoes in intereruptive stage, - on the other hand, this water, according to its isotopic composition, suffered no or little contamination by meteoric waters (ice and snow at this elevation have mean $\delta^{18} \mathrm{O}=-20 \% 0$ and $\delta \mathrm{D}=-150 \%$; Y. Muraviev, pers. commun., 1990).

Formulas for temperature and $f_{\mathrm{O}_{2}}$ calculations were obtained through interpolation of data from Robie et al. (1978), as log $K=A+B / T$. Their accuracy is no less than $0.05 \log$ units.

$$
T_{\mathrm{C}}\left({ }^{\circ} \mathrm{C}\right)=1778 /\left(1.61-\log K_{\mathrm{C}}\right)-273
$$

where $K_{\mathrm{C}}=x_{\mathrm{CO}} \cdot x_{\mathrm{H}_{2} \mathrm{O}} / x_{\mathrm{CO}_{2}} x_{\mathrm{H}_{2}}$ and $x_{\mathrm{i}}$ are mole fractions;

$$
T_{\mathrm{S}}\left({ }^{\circ} \mathrm{C}\right)=11907 /\left(4.75-\log K_{\mathrm{S}}\right)-273
$$

where $K_{\mathrm{S}}=x_{\mathrm{H}_{2} \mathrm{O}}^{2} \cdot x_{\mathrm{H}_{2} \mathrm{~S}} / x_{\mathrm{H}_{2}}^{3} \cdot x_{\mathrm{SO}_{2}}$

$$
\begin{aligned}
& \log f_{\mathrm{O}_{2}}(\mathrm{H})=-25932 / T+5.72 \\
& \quad-2 \log \left(x_{\mathrm{H}_{2}} / x_{\mathrm{H}_{2} \mathrm{O}}\right) \\
& \log f_{\mathrm{O}_{2}}(\mathrm{C})=-29487 / T+9.05 \\
& \quad-2 \log \left(x_{\mathrm{CO}} / x_{\mathrm{CO}_{2}}\right)
\end{aligned}
$$

$$
\begin{aligned}
& \log f_{\mathrm{O}_{2}}(\mathrm{~S})=-14025 / T+1.08 \\
& \quad+\log \left(x_{\mathrm{SO}_{2}} x_{\mathrm{H}_{2}} / x_{\mathrm{H}_{2} \mathrm{~S}}\right) \\
& \log f_{\mathrm{S}_{2}}=-4722 / T+2.56 \\
& \quad-2 \log \left(x_{\mathrm{H}_{2}} / x_{\mathrm{H}_{2} \mathrm{~S}}\right)
\end{aligned}
$$

For the isotopic fractionation factor between $\mathrm{H}_{2}$ and $\mathrm{H}_{2} \mathrm{O}$ in the temperature range $800-1300^{\circ} \mathrm{C}$, interpolation of Richet et al. (1977) data give:

$$
\Delta_{\mathrm{H}}=1000 \ln \alpha_{\mathrm{H}_{2}-\mathrm{H}_{2} \mathrm{O}}=-151.6+361842 / T
$$

The calculations show that the high water content of our samples is consistent with equilibrium temperatures close to but lower than 


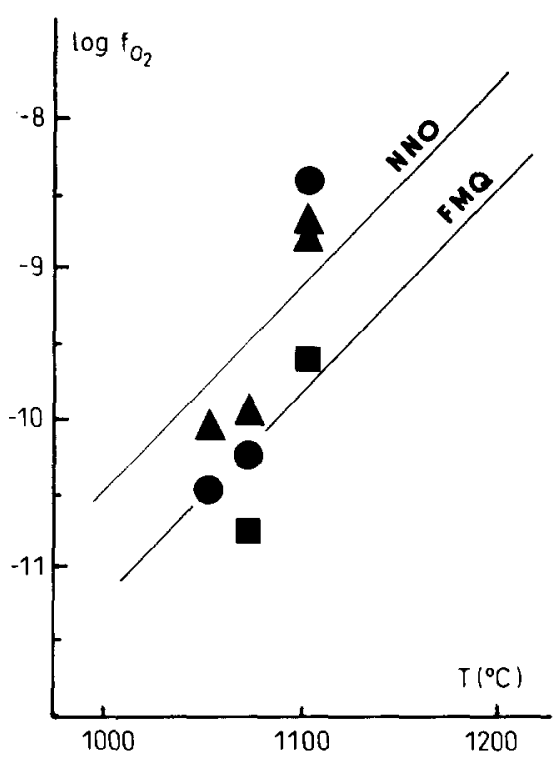

Fig. 1. Relationship between the measured temperature and oxygen fugacity $f_{\mathrm{O}_{2}}$ of the gases calculated from oxidation reactions (3-5). The curves correspond to the FMQ and NNO oxygen buffers, respectively. $f_{\mathrm{O}_{2}}$ values from: triangles $x_{\mathrm{H}_{2}} / x_{\mathrm{H}_{2} \mathrm{O}}$ ratio; circles $-x_{\mathrm{CO}} / x_{\mathrm{CO}_{2}}$ ratio; squares $-x_{\mathrm{H}_{2} \mathrm{~S}} / x_{\mathrm{SO}_{2}}$

the meaured temperatures. Temperature $T_{\mathrm{C}}$ is higher than $T_{\mathrm{S}}$, though unrealistically high for sample $1 . T_{\mathrm{S}}$ temperatures are lower by about $100^{\circ} \mathrm{C}$ than the measured ones, which most probably reflects losses and/or redistribution of sulfur species in the sampling system. Lower $f_{\mathrm{O}_{2}}$ low $f_{\mathrm{S}_{2}}$ values correlate with low "sulfur" temperatures.

Figure 1 shows the relationship between the measured temperatures and values of oxygen fugacity calculated from equations ( 8 to $10)$. The spread in calculated $f_{\mathrm{O}_{2}}$ values is within one log unit for samples 1 and 2 , and somewhat higher for samples 3 and 4 which also are much more oxidized (low $\mathrm{CO}, \mathrm{H}_{2}$ and $\mathrm{H}_{2} \mathrm{~S}$ ). The points for samples 1 and 2, calculated from ratio $x_{\mathrm{H}_{2}} / x_{\mathrm{H}_{2}} \mathrm{O}$, lie between the fayalite-magnetite-quartz (FMQ) and nickelnickel oxide (NNO) oxygen buffers, i.e. in the redox field typical of most basaltic and andesitic gases (Allard et al., 1977; Gerlach, 1983).
The values of $f_{\mathrm{O}_{2}}$ calculated from equation (10) prove once again that the use of sulfur species for thermodynamical calculations is less reliable. In our case, one cannot exclude errors in analytical determinations, due to the very small amount of sulfur in the gases from the 1988 eruption of Klyuchevskoy.

\section{Chemical evidences of magma degassing}

The main chemical features of our samples are their high water content, high $\mathrm{Cl}$ and $\mathrm{F}$ content, and low sulfur content. In that respect, they look very similar to the gases sampled by I.A. Menyailov et al. during the Southern Breakthrough of the Large Tolbachik Fissure eruption (LTFE) (Menyailov et al., 1984). In Table 3, these data on both Klyuchevskoy and Tolbachik are compared with other magmatic gases from basaltic volcanoes. It is noteworthy that these basaltic gases generally contain not less than 3 mole $\%$ sulfur, not less than $5 \% \mathrm{CO}_{2}$, while $\mathrm{H}_{2} \mathrm{O}$ does not exceed $92.5 \%$ in the most hydrous gases (Surtsey, Iceland). In contrast, the Klyuchevskoy gases as well as the gases from the Southern Breakthrough of LTFE, contain no more than $0.2 \% \mathrm{~S}$ but up to $98 \%$ $\mathrm{H}_{2} \mathrm{O}$. We stress again that isotopic evidences support that this water is of magmatic origin and exclude any significant admixture of meteoric water. A likely explanation of the chemical peculiarity of Klyuchevskoy samples is that they reflect the late degassing of basaltic magma previously depleted in carbon dioxide. Indeed, the solubility of $\mathrm{CO}_{2}$ in basalt is many times lower than that of water and halogens (Kadik et al., 1971; Stolper and Holloway, 1987). Figure 2 shows the correlational dependencies of atomic ratios $\mathrm{H} / \mathrm{C}$ and $\mathrm{S} / \mathrm{C}$ for the basaltic gases listed in Table 3, as constructed by Gerlach (1983), as well as for both Klyuchevskoy and Tolbachik gases. It can be seen that the plots for all concerned volcanoes follow a similar linear trend, with a slope of about 1 . The Klyuchevskoy and 
TABLE 3

Chemical composition (mole \%) of high-temperature basaltic gases (modified from Gerlach, 1983)

\begin{tabular}{|c|c|c|c|c|c|c|c|c|c|c|c|c|}
\hline Volcano & $\begin{array}{l}\text { Year of } \\
\text { sampling }\end{array}$ & $\mathrm{H}_{2} \mathrm{O}$ & $\mathrm{H}_{2}$ & $\mathrm{CO}_{2}$ & $\mathrm{CO}$ & $\mathrm{SO}_{2}$ & $\mathrm{~S}_{2}$ & $\mathrm{H}_{2} \mathrm{~S}$ & $\mathrm{HCl}$ & $\mathrm{t}\left({ }^{\circ} \mathrm{C}\right)$ & $\mathrm{H} / \mathrm{C}$ & $\mathrm{S} / \mathrm{C}$ \\
\hline \multirow[t]{3}{*}{ Surtsey } & 1964 & 81.13 & 2.37 & 9.29 & 0.69 & 3.15 & 0.13 & 0.64 & 0.81 & 1125 & 16.7 & 3.34 \\
\hline & 1965 & 87.88 & 3.12 & 6.43 & 0.39 & 2.72 & 0.10 & 0.63 & 0.43 & 1125 & 26.7 & 1.98 \\
\hline & 1967 & 92.47 & 1.74 & 3.31 & 0.11 & 3.74 & 0.02 & 0.15 & 1.16 & 1125 & 55.1 & 1.14 \\
\hline \multirow[t]{3}{*}{ Erta Ale } & 1971 & 71.65 & 1.62 & 18.88 & 0.83 & 10.17 & 0.68 & 1.10 & - & 1075 & 7.43 & 1.65 \\
\hline & 1973 & 70.35 & 2.36 & 18.42 & 1.55 & 6.74 & 0.15 & 0.38 & - & 1210 & 7.28 & 0.35 \\
\hline & 1974 & 78.28 & 1.76 & 13.08 & 0.60 & 8.34 & 0.36 & 1.08 & - & 1130 & 11.8 & 0.72 \\
\hline Ardoukoba & 1978 & 78.71 & 1.73 & 4.02 & 0.17 & 15.38 & 1.51 & 1.80 & - & 1070 & 38.4 & 4.46 \\
\hline \multirow[t]{4}{*}{ Kilauea } & $\mathrm{J}-8^{\mathrm{a}}$ & 37.09 & 0.49 & 48.90 & 1.51 & 11.84 & 0.02 & 0.04 & 0.08 & 1170 & 1.49 & 0.24 \\
\hline & $\mathrm{J}-13^{\mathrm{a}}$ & 69.29 & 1.01 & 17.82 & 0.62 & 10.93 & 0.03 & 0.08 & 0.21 & 1175 & 7.62 & 0.60 \\
\hline & $1982^{b}$ & 47.07 & 0.57 & 6.24 & 0.13 & 44.32 & - & 1.68 & - & 1070 & 15.26 & 6.94 \\
\hline & $1983^{h}$ & 85.85 & 1.45 & 1.43 & 0.05 & 10.61 & - & 0.61 & - & 1110 & 118 & 7.58 \\
\hline Mauna Loac & 1984 & 69.40 & 0.66 & 4.57 & 0.16 & 24.7 & - & 0.38 & 0.015 & 1130 & 296 & 5.30 \\
\hline Etna & 1970 & 49.91 & 0.54 & 26.06 & 0.54 & 38.54 & 0.38 & 0.27 & - & 1075 & 3.79 & 1.47 \\
\hline Nyiragongo & 1959 & 45.90 & 1.59 & 45.44 & 2.70 & 2.30 & 0.55 & 1.41 & - & 1020 & 1.97 & 0.09 \\
\hline \multirow[t]{2}{*}{ Tolbachik $^{d}$} & NB 1976 & 78.56 & 3.01 & 4.87 & 0.39 & 0.03 & - & 0.16 & 0.57 & 1000 & 31.0 & 0.036 \\
\hline & SB 1976 & 97.77 & 0.76 & 0.08 & 0.001 & 0.13 & - & 0.11 & 0.74 & 1100 & 2433 & 2.96 \\
\hline \multirow[t]{2}{*}{ Klyuchevskoye } & Jul 18,1988 & 90.84 & 1.70 & 4.47 & 0.16 & 0.11 & - & 0.005 & 2.02 & 1050 & 40.0 & 0.025 \\
\hline & Aug 25, 1988 & 98.73 & 0.59 & 0.12 & 0.0001 & 0.09 & - & 0.0002 & 1.42 & 1100 & 1640 & 0.76 \\
\hline
\end{tabular}

Notes: a Gases of so-called J-series from classical collection of Jagar 1918-1919; ${ }^{b, c}$ after Greenland (1987); ${ }^{d}$ after I.A. Menyailov et al., 1984; ' 'authors' data.

Tolbachik samples display specially high $\mathrm{H} / \mathrm{C}$ ratios, due to their higher water content.

Such a pattern is typical of a progressive depletion of $\mathrm{CO}_{2}$ in the melts, with gradual and concomitant enrichment of both water and sulfur in the gas released during the course of eruptions (Gerlach, 1983). Nevertheless, it remains to explain why the sulfur content of both Klyuchevskoy and Tolbachik gases are so low compared to most other basaltic gases. Gerlach (1980) noted relatively low sulfur content in gas from Nyiragongo (Africa), which he explained by low $f_{\mathrm{O}_{2}}$ conditions, (lower than FMQ buffer) of the gasmelt system, rather than by a depletion of sulfur in the magma, since Nyiragongo lavas contain up to $0.5 \mathrm{wt} . \% \mathrm{~S}$, i.e. much more than mid-ocean ridge basalts $(\sim 0.1 \mathrm{wt} . \% \mathrm{~S})$. It is known that the solubility of sulfur in silicate melts depends on various parameters, among which the Fe content and the oxygen fugacity of the melt (Haughton et al., 1974; Katzura and Nagashima, 1974; Whitney, 1985). At low $f_{\mathrm{O}_{2}}$ sulfur occurs in the melt mostly as Fesulphides (pyrrotine) and the sulfur fugacity is controlled by the equilibrium:

$\mathrm{FeS}+1 / 2 \mathrm{O}_{2}=\mathrm{FeO}+1 / 2 \mathrm{~S}_{2}$

i.e. by the $(\mathrm{FeO} / \mathrm{FeS})$ ratio of the melt independently to its total sulfur content.

From the above considerations, we may propose the following interpretation of the chemical features in the gases from Klyuchevskoy. As a result of eruptive activity and degassing at the summit crater of Klyuchevskoy during the last eruptive cycle ending in 1988, considerable loss of $\mathrm{CO}_{2}$ and sulfur occurred from the feeding magma. Such degassing resulted in a relative enrichment of water and halogens $(\mathrm{HCl}, \mathrm{HF})$ in the residual magma and gases. Sulfur in out- 


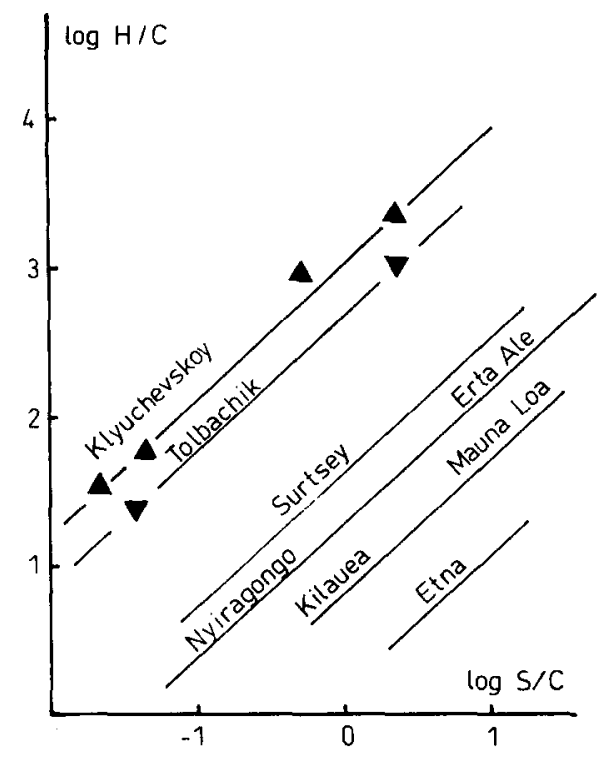

Fig. 2. Correlated variations of $\mathrm{H} / \mathrm{S}$ and $\mathrm{S} / \mathrm{C}$ atomic ratios in high-temperature gases of basaltic volcanoes. After Gerlach (1983), except for data on Klyuchevskoy (this paper), Tolbachik (Menyailov et al., 1984) and Mauna Loa (Greenland, 1987a), which were added.

gassed, crystallizing basalt would occur as sulphide, while in the gas phase its fugacity will be controlled by both $f_{\mathrm{O}_{2}}$ and $(\mathrm{FeS} / \mathrm{FeO})_{\text {melt }}$ ratio. Further analysis of volatile abundances and oxygen fugacity in basaltic glasses from the 1988 flank eruption of Klyuchevskoy will allow to verify this point.

\section{Carbon isotopes and outgassing degree of the melt}

Our data on carbon isotopes provide further insight into the above discussion. The $\delta^{13} \mathrm{C}$ measured on one sample of $\mathrm{CO}_{2}$ (sample 2) was $-11.6 \%$ (PDB). It is known that mantle-magmatic carbon dioxide has an average isotopic composition of $-6 \pm 1 \%$ (Allard, 1983; Des Marais and Moor, 1984; Javoy et al., 1986). $\delta^{13} \mathrm{C}$ in magmatic gases from basaltic volcanoes range from $-6 \%$ in Afar (Allard et al., 1977; Allard, 1979), -4\%o at Etna (Allard, 1983), to -4 to $-2.5 \%$ in Hawaii (Friedman et al., 1987). Menyailov et al. (1984) reported a $\delta^{13} \mathrm{C}$ of $-3.4 \%$ for hightemperature gases from the Northern Breakthrough of the LTFE.

Now, there is a significant isotopic fractionation of about $4 \% 0$ between basalt melt and $\mathrm{CO}_{2}$ at magmatic temperatures, in favour of the $\mathrm{CO}_{2}$ (Javoy et al., 1978). New experiments of Belomestnykh and Shilobreeva (1989) with basalts from the Klyuchevskoy volcano at $1250^{\circ} \mathrm{C}$ and $3 \mathrm{kbar}$ pressure give the average value of $\Delta^{13} \mathrm{C}$ (melt - fluid) $+4.2 \pm 0.8 \%$. Accordingly, assuming the $\mathrm{CO}_{2}$ released with $\delta^{13} \mathrm{C}_{\mathrm{CO}_{2}}=-11.6 \%$ was in equilibrium with the $\mathrm{CO}_{2}$ dissolved in the melt, this latter would have had a $\delta^{13} \mathrm{C}$ of about $-16 \%$, i.e. much lower than the "normal" magmatic values. Considering a Rayliegh distillation mechanism for $\mathrm{CO}_{2}$ degassing from the melt (no extraneous source of $\mathrm{CO}_{2}$ ), we can estimate the degree of melt outgassing:

$\Delta_{\mathrm{C}}^{13}=-6-(-16)=\Delta_{\mathrm{o}}^{13} \mathrm{C} \ln (1-F)$

where $\Delta_{o}$ is the equilibrium isotopic fractionation factor of $-4.2 \% o$ and $F$ is the degree of outgassing. Hence $F \simeq 91 \%$.

If our assumptions are true, than the $\mathrm{CO}_{2}$ outgassing degree of the Klyuchevskoy melt in July was of about $90 \%$.

Our arguments from carbon isotopes are based on only one figure and thus are rather speculative. However, this assumption is consistent with both the features of the Klyuchevskoy eruption and the chemical characteristics of the collected gases. A value of $-30 \%$ was obtained by Menyailov et al. (1984) for $\delta^{13} \mathrm{C}$ of $\mathrm{CO}_{2}$ from the Tolbachik Southern Breakthrough, during the latest stage of the eruption (October 1976). Such a low $\delta^{13} \mathrm{C}$ may also indicate a large outgassing degree of the corresponding melt toward the end of the eruption.

On the other hand, one may propose that low $\delta^{13} \mathrm{C}$ of $\mathrm{CO}_{2}$ from the Klyuchevskoy gases is due to some contribution of crustal reduced carbon from metamorphic rocks of the basement to the magmas. The enrichment of the 
magmatic water in deuterium (sample 2) may also be connected with crustal contamination.

\section{Conclusions}

(1) High-temperature $\left(1000-1100^{\circ} \mathrm{C}\right)$ basaltic gases from the Klyuchevskoy 1988 flank eruption are particularly rich in water and poor in sulfur. Their chemical composition was close to chemical equilibrium at sampling temperatures. Their oxygen fugacity, calculated from their molar composition, ranges between the FMQ and NNO oxygen buffers.

(2) Although particularly enriched in this gases, water has an isotopic composition typical of "primary" magmatic water. The isotopic composition of molecular hydrogen is consistent with isotopic equilibrium between $\mathrm{H}_{2} \mathrm{O}$ and $\mathrm{H}_{2}$ at the emission temperatures of $1000-1100^{\circ} \mathrm{C}$.

(3) The amounts of carbon and sulfur in the gases, the correlated trend of $\mathrm{H} / \mathrm{C}$ and $\mathrm{S} / \mathrm{C}$ ratios, as well as, the occurrence of isotopically light $\mathrm{CO}_{2}$ compared to mantle carbon, are taken as indication that considerable outgassing of the melt took place prior to or during the 1988 flank eruption of Klyuchevskoy.

\section{Acknowledgements}

The authors wish to express their gratitude to A.Y. Ozerov for his help in collecting the samples. We would also like to thank B.G. Pokrovsky and A.L. Devirtz for measurements of isotopic composition of molecular hydrogen. An anonymous referee and Patrick Allard provided many helpful comments which helped improve the quality of the manuscript.

\section{References}

Allard, $\mathrm{P}, 1979 .{ }^{13} \mathrm{C} /{ }^{12} \mathrm{C}$ and ${ }^{34} \mathrm{~S} /{ }^{32} \mathrm{~S}$ ratios in magmatic gases from ridge volcanism in Afar. Nature, 282: 56-58.
Allard, P., 1980. Composition isotopique du carbone dans les gas d'un volcan d'arc: le Momotombo (Nicaragua). C.R. Acad. Sci. Paris, 290: 1525-1528.

Allard, P., 1983. The origin of hydrogen, carbon, sulfur, nitrogen and rare gases in volcanic exhalations; evidence from isotope geochemistry. In: H. Tazieff and J.-C. Sabroux (Editors), Forecasting Volcanic Events. Elsevier, Amsterdam. pp. 337-386.

Allard, P., Le Guern, F. and Sabroux, J.-C., 1977. Thermodynamic and isotopic studies of eruptive gases. Geothermics, 5: 37-40.

Belomestnykh, A.V. and Shilobreeva, S.N., 1989. Carbon isotopes fractionation in the system basalt melt- $\mathrm{CO}_{2}-\mathrm{H}_{2} \mathrm{O}$ at 3 kbar pressure and $1250^{\circ} \mathrm{C}$. Abstr. 12 Symp. on Stable Isotopes in Geochemistry, Vernadsky Inst., Moscow, pp. 188-189 (in Russian).

Basharina, L.A., 1963. Exhalations from the Klyuchevskoy volcano flank craters at different stages of solidification of lava. In: B.I. Piip (Editor), Volcanism in Kamchatka and Some Other Regions of the USSR. Nauka, Moscow, pp. 169-227 (in Russian).

Des Marais, D.J. and Moor, J.G., 1984. Carbon and its isotopes in mid-oceanic basaltic glasses. Earth Planet. Sci. Lett., 69: 43-57.

Fedotov, S.A., Zharinov, N.A. and Gorelchik, V.I., 1988. Deformations and earthquakes of Klyuchevskoy volcano; model of its activity. Volcanol. Seismol., 2: 2-42 (in Russian).

Friedman, I., Gilason, J. and Jackson, T., 1987. Variations of $\delta^{1.3} \mathrm{C}$ in fumarolic gases from Kilauea volcano. Volcanism in Hawaii. U.S. Geol. Surv., Prof. Pap., 1350: 805-808.

Gerlach, T.M., 1980. Chemical characteristics of the volcanic gases from Nyiragongo lava lake and generation of $\mathrm{CH}_{4}$-rich fluid inclusion in alkaline rocks. J. Volcanol. Geotherm. Res., 8: 177-189.

Gerlach, T.M., 1983. Intrinsic chemical variations in hightemperature volcanic gases from basic lavas. In: H. Tazieff and J.C. Sabroux (Editors), Forecasting Volcanic Events. Elsevier, Amsterdam, pp. 323-336.

Giggenbach, W., 1975. A simple method for the collection and analysis of volcanic gases samples. Bull. Volcanol., 39: 132-145.

Greenland, L.P., 1987. Hawaiian eruptive gases. Volcanism in Hawaii. U.S. Geol. Surv., Prof. Pap., 1350: 759-770.

Greenland, L.P., 1987a. Composition of gases from the 1984 eruption of Mauna Loa volcano. U.S. Geol. Surv., Prof. Pap., 1350: 781-790.

Haughton, D.R., Roeder, P.L. and Skinner, B.J., 1974. Solubility of sulfur in mafic magmas. Econ. Geol., 69: 451467.

Javoy, M., Pineau, F. and Iiyama, I., 1978. Experimental determination of the isotopic fractionation between $\mathrm{CO}_{2}$ and carbon dissolved in tholeiitic magma; a preliminary study. Contrib. Mineral. Petrol., 67: 35-39. 
Javoy, M., Pineau. F. and Delorme, H., 1986. Carbon and nitrogen isotopes in the mantle. Chem. Geol., 57: 41-62.

Kadik, A.A., Lebedev, E.B. and Khitarov, N.I., 1971. The Water in Magmatic Melts. Nauka, Moscow, $267 \mathrm{pp}$.

Katzura, T. and Nagashima, S., 1974. Solubility of sulfur in magmas. Geochim. Cosmochim. Acta, 38: 517-531.

Khrenov, A.P., Antipin, V.S., Chuvashova, L.A. and Smirnova, E.V., 1989. Petrochemical and geochemical features of basalts from Klyuchevskoy volcano. Volcanol. Seismol., 3: 3-15 (in Russian).

Kirsanov, I.T., Ponomarev, G.P. and Shteinberg, G.S., 1973. Some regularities in Klyuchevskoy volcano eruptions. Bull. Volcanol. Stantsii, 49: 93-98 (in Russian).

Mathez, E.A., 1976. Sulfur solubility and magmatic sulfides in submarine basalt glass. J. Geophys. Res., 81: 4269-4275.

Menyailov, I.A., Nikitina, L.P. Buachidze, G.I. and Rozhkov, A.M., 1983. Carbon isotopic composition of $\mathrm{CO}_{2}$ from volcanic gases in Kamchatka and Kuriles. Volcanol. Seismol., 2: 36-44 (in Russian).

Menyailov, I.A., Nikitina, L.P. and Shapar, V.N., 1984. Geochemical features of volcanic gases. In: S.A. Fedotov and E.K. Markhinin (Editors), The Large Tolbachik Fissure Eruption. Nauka, Moscow, pp. 285-308 (in Russian).

Poreda, R., 1985. Helium-3 and deuterium in back-arc basalts Lau Basin and the Mariana Trough. Earth Planet. Sci. Lett., 73: 244-254.

Richet, P., Bottinga, Y. and Javoy, M., 1977. A review of hydrogen, carbon, nitrogen, oxygen, sulfur and chlorine stable isotope fractionation among gaseous molecules. Annu. Rev. Earth Planet. Sci., 5: 65-110.
Robie, R., Hemingway, B.S. and Ficher, J.R., 1978. Thermodynamic properties of mineral and related substances at 298.15 K and 1 bar pressure. U.S. Geol. Surv., Bull., 1452, 456 pp.

Sakai, H. and Matsubaya, O., 1977. Stable isotopic studies of Japanese geothermal system. Geothermics, 5: 97-124.

Serafimova, E.K., 1979. Mineralogy of Sublimates from Kamchatkan Volcanoes. Nauka, Moscow, 168 pp. (in Russian).

Stolper, E. and Holloway, J.R., 1988. Experimental determination of the solubility of carbon dioxide in molten basalt at low pressure. Earth Planet. Sci. Lett., 87: 397-408,

Taran, Y.A., 1985. Fumarolic activity of Koryaksky volcano in 1983. Volcanol. Seismol., 3: 82-85 (in Russian)

Taran, Y.A., Pokrovsky, B.G. and Dubik. Y.M., 1989. Isotopic composition and origin of water from andesitic magmas. Dokl. Acad. Sci. USSR, N. 304: 440-443 (in Russian).

Taran, Y.A., Vakin, E.A., Pilipenko, V.P. and Rozhkov, A.M., 1991. A geochemical model for fumaroles of the Muthovsky volcano, Kamchatka, USSR. J. Volcanol. Geotherm. Res., in press.

Taylor, H.P., 1979. Oxygen and hydrogen in hydrothermal mineral deposits. In: H.L. Barnes (Editor), Geochemistry of Hydrothermal Ore Deposits. Wiley-Interscience, New York, NY, pp. 236-277.

Tsitsishvilli, G.V., Sabelashvili, S.D. and Andronikashvili, T.G., 1975. Chromatographic separation of argon, oxygen and nitrogen on syntetic zeolites. Zavod. Lab., 4: 398-401 (in Russian).

Whitney, J.A., 1985. Fugacities of sulphurous gases in pirrotite-bearing magmas. Am. Mineral., 69: 69-78. 